\title{
DOAS FOR FLUE GAS MONITORING-III. IN-SITU MONITORING OF SULFUR DIOXIDE, NITROGEN MONOXIDE AND AMMONIA
}

\author{
JOHAN MELLQVIST, ${ }^{a, b}$ HÅKAN AXELSSON, ${ }^{c}$ and ARNE ROSÉN ${ }^{a}$ \\ ${ }^{a}$ Department of Physics, Chalmers University of Technology and Göteborg University, S-412 96 \\ Göteborg, ${ }^{b}$ Swedish Environmental Research Institute (IVL), P.O. Box 47086, S-402 58 Göteborg, and \\ 'Vattenfall Utveckling AB, Folkungag. 20, S-411 02 Göteborg, Sweden
}

(Received 14 December 1995)

\begin{abstract}
A methodology is described for the in-situ detection of $\mathrm{NO}, \mathrm{NH}_{3}$ and $\mathrm{SO}_{2}$ in flue gases by DOAS (Differential Optical Absorption Spectroscopy). In order to perform accurate measurements of the concentration it is necessary to compensate for the temperature dependence of the absorption cross-sections as well as for potential deviations from the Beer-Lambert law (nonlinearity effects). From the experimental data in two previous papers, empirical equations were derived for the compensation of the nonlinearity and temperature effects. These were used to compensate obtained concentration values of $\mathrm{NO}$ and $\mathrm{SO}_{2}$ retrieved from DOAS spectra that were recorded in a flue gas at $413 \mathrm{~K}$. The measurements of $\mathrm{SO}_{2}$ showed that in a concentration interval of $500-1600 \mathrm{ppm}$ at $413 \mathrm{~K}$, the resulting systematic discrepancies between the DOAS and a conventional reference system decreased from 40 to only $2 \%$ when compensating the DOAS data. The maximum random difference was approximately $15 \%$. In the same manner the systematic difference for NO decreased from 23 to $1 \%$, with a maximum random error of $5 \%$, for concentrations between 60 and $160 \mathrm{ppm}$. The measurements of $\mathrm{NH}_{3}$ demonstrated the versatility of the DOAS technique for time resolved in-situ measurements $(<20 \mathrm{sec})$, and also the feasibility of the technique for measuring several species simultaneously. The measurement methodology developed for $\mathrm{NH}_{3}$ was more complicated than for $\mathrm{NO}$ and $\mathrm{SO}_{2}$ and required a larger amount of laboratory calibrations. In the spectral evaluation procedure of $\mathrm{NH}_{3}$ hot bands were utilized for flue gas temperatures above $450 \mathrm{~K}$. Copyright (C) 1996 Elsevier Science Ltd
\end{abstract}

\section{INTRODUCTION}

Combustion of fossil fuel is today the main source of sulfur and $\mathrm{NO}_{x}$ emissions to the atmosphere. The sulfur emitted to the atmosphere will when deposited on the ground cause severe effects on many ecosystems by lowering $\mathrm{pH}$ values. The increased acidity in the ground will dissolve both $\mathrm{Al}$ as well as nutritive substances such as $\mathrm{Ca}, \mathrm{Mg}$ and $\mathrm{K}$ from the soil, ${ }^{2}$ which in turn causes undernourishment in the soil. Deposition of oxidized nitrogen can also acidify the soil under certain conditions as well as cause eutrofication. An additional severe effect of $\mathrm{NO}_{x}$ emissions is the formation of tropospheric ozone by reaction of $\mathrm{NO}_{x}$ with hydrocarbons or $\mathrm{CO}$ in the air. ${ }^{3} \mathrm{On}$ a global scale increasing emissions of $\mathrm{NO}_{x}, \mathrm{CO}$ and $\mathrm{CH}_{4}$ to the troposphere, have caused increasing background concentrations of $\mathrm{O}_{3}$, which in turn can induce severe effects on plant growth and on the overall chemistry of the atmosphere. ${ }^{4}$ In order to decrease the emissions of sulfur and nitrogen oxides, abatement strategies enforcing environmental taxes on polluters could be very efficient, and this has been implemented in Sweden since 1992 on emissions of $\mathrm{SO}_{2}, \mathrm{NO}_{2}$ and $\mathrm{CO}_{2}$.

Such strategies require however, reliable and accurate measurement techniques. In this paper DOAS technique (Differential Optical Absorption Spectroscopy) applied for in-situ measurements of flue gases has been studied, and compared to other, more conventional techniques, for flue gas monitoring. The DOAS technique is versatile for the detection of several species of environmental interest in flue gases, such as $\mathrm{NO}, \mathrm{NO}_{2}, \mathrm{SO}_{2}$ and $\mathrm{NH}_{3}$. It is based on transmitting broadband u.v. light through a gas and then recording the differential absorption, i.e., the difference between local 
maxima and minima in the absorption spectrum of the target species. The technique has been widely used for measurements in the atmosphere ${ }^{5-8}$ and in this work the technique has been applied for in-situ measurements of flue gases, by transmitting the light directly through the cross-section of a flue gas channel. It is not justified to apply the technique straightforwardly, however, since flue gases have high and variable temperatures which may affect the differential absorption features significantly. In addition the optical path-lengths are determined by the dimensions of the flue gas channels, and this may lead to such large optical depths that the absorption of the gases will deviate from the Beer-Lambert law and become nonlinear. The temperature effect and the nonlinearity effect have been studied in two previous papers, which will be referred to as Paper $\mathrm{I}^{9}$ and Paper II, ${ }^{10}$ respectively. In this study the results in Papers I and II have been applied in order to improve the performance of the DOAS technique for in-situ measurements of flue gases.

Reliable and accurate in-situ measurements of flue gases are not only of interest for the implementation of environmental taxation; in-situ measurements also make possible time resolved measurements of polar species, which usually are very difficult to measure by extractive techniques. This makes it possible to use the in-situ technique in feedback systems to control the combustion or to control cleaning processes, for example $\mathrm{NO}_{x}$-reduction by injection of $\mathrm{NH}_{3}$ in $\mathrm{SNCR}$ (Selective Non-Catalytic Reaction) converters. ${ }^{11}$

\section{EXPERIMENTAL}

\subsection{DOAS equipment for in-situ monitoring}

A schematic overview of the DOAS equipment used for in-situ measurements in flue gases is displayed in Fig. 1. The DOAS set up follows the general design of Platt and Perner ${ }^{12}$ and has been described rather thoroughly in Paper I. ${ }^{9}$ Ultraviolet/visible light from a xenon arc lamp is transmitted through a measurement path by telescopes and is then via an optical fiber focused on to the entrance slit of a Thermo Jarrel-Ash spectrometer $(275 \mathrm{~mm}, \mathrm{f} / 3.8$ Czerny-Turner). The spectrometer is equipped with a rotating slotted disc set-up replacing the exit slit. A photomultiplier tube detects the transmitted light by taking 1024 samples during one scan, i.e., during the passage

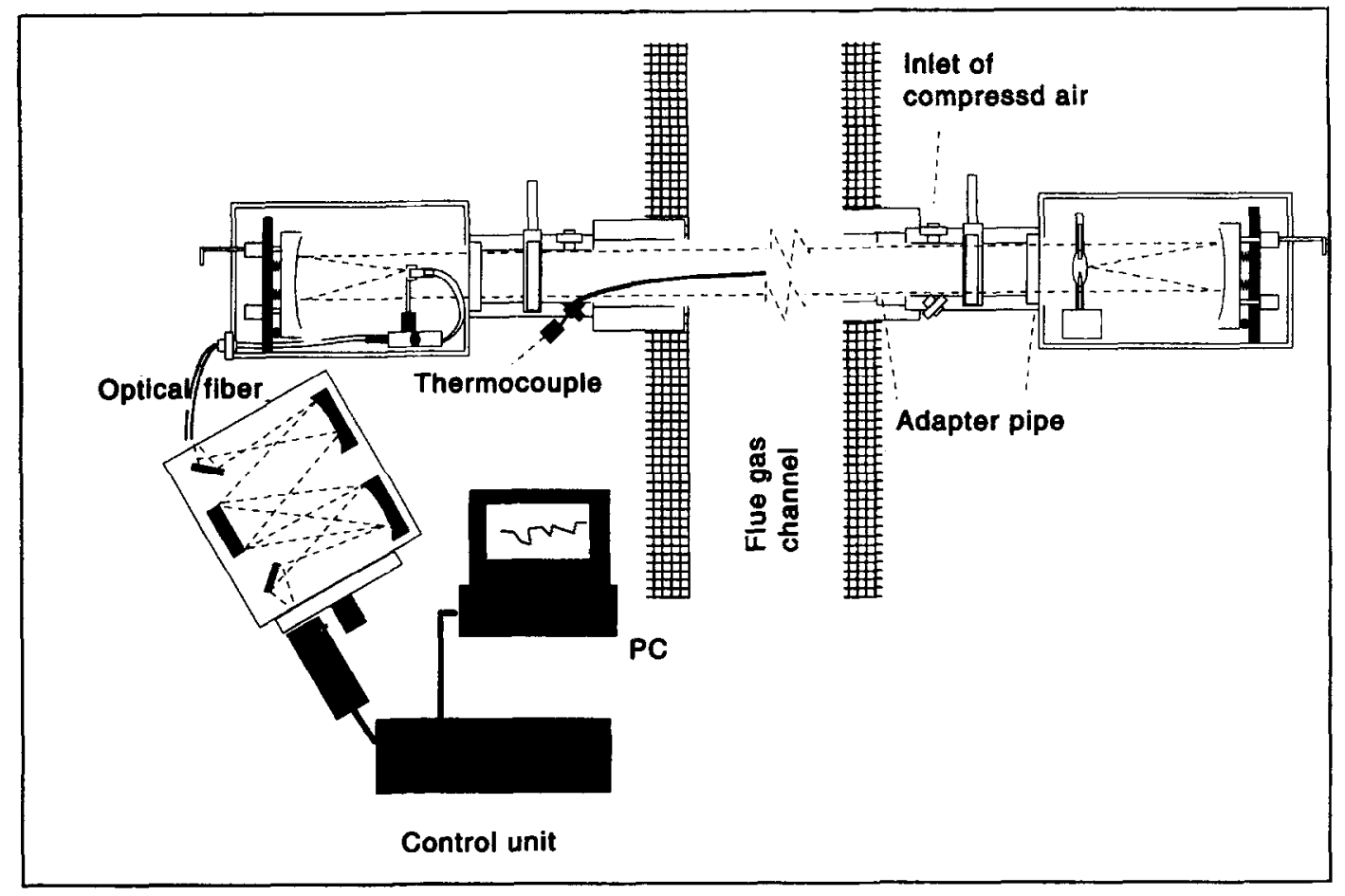

Fig. 1. A schematic overview of the DOAS equipment used for flue gas measurements. 
of each slit in front of the focal plane of the spectrometer. The signal is amplified and sent to a PC with a custom-made MCA (multichannel analyzer) plug-in card dividing each scan into 1024 channels. The spectral resolution in the measurements in this work was $0.3 \mathrm{~nm}$ in the range from 200 to $230 \mathrm{~mm}$ and 0.23 at $300 \mathrm{~nm}$, with a Gaussian shaped instrument function and an oversampling factor of 8 .

The telescopes were of Newtonian type with a focal ratio of $f / 3$ and a focal-length of $150 \mathrm{~mm}$. The effective diameter of the entrance quartz-windows (Suprasil ${ }^{\mathrm{TM}}$ ) was $55 \mathrm{~mm}$. The main mirrors were off axis parabolic mirrors with a surface finish of $0.10 \mu \mathrm{m}$, coated with $\mathrm{Al}\left(\mathrm{MgF}_{2}\right)$. The optical fibers were made of pure fused silica (Superguide $\mathrm{G}^{\mathrm{TM}}$ ). The telescopes were attached by stainless steel adapters which in turn were screwed on to flanges made of $3^{\prime \prime}$ wide and $50 \mathrm{~cm}$ long pipes, that were welded on to the walls of the flue gas channels. The telescopes were equipped with double windows, with one of them made removable to make cleaning possible, without having to change the optical set-up. The flue gas temperature was measured by thermocouples (type $\mathrm{K} /$ chromel-alumel).

An error source that has to be considered, when performing in-situ measurements in the way shown in Fig. 1, is to what extent the gases in the flue gas channel diffuse into the adapter pipes. If there is any significant diffusion, an overestimation of the measured concentration will be caused. To prevent flue gases and particulate matter from diffusing into the adapter pipes, these were purged with compressed air, which also kept the quartz windows clean.

A measurement of the amount of NO that diffused into the adapter pipes when purging these with compressed air is shown in Fig. 2. The NO concentration was here measured at different locations in the $50 \mathrm{~cm}$ long adapter pipe by insertion of a Teflon tubing connected to a conventional nondispersive infrared absorption instrument (Binos). It can be seen that the diffusion of NO caused a slightly higher concentration in the adapter pipe than in the ambient air. An additional total column of approximately $1.8 \mathrm{ppm} \cdot \mathrm{m}$ was therefore added to the total column inside the flue gas channel which was $56 \mathrm{ppm} \cdot \mathrm{m}$. This resulted in an overestimation of the flue gas concentration of $3 \%$. A concentration gradient in the flue gas channel was also seen and this instead causes an underestimation of the concentration of $6 \%$. Concentration gradients and diffusion into the adapter pipes can thus cause uncertainties in the order of $5 \%$ when short optical paths are being utilized.

\section{MEASUREMENT STRATEGY}

In this section a methodology will be described on how to derive path averaged concentrations from DOAS spectra, recorded in flue gases with variable temperatures and concentrations.

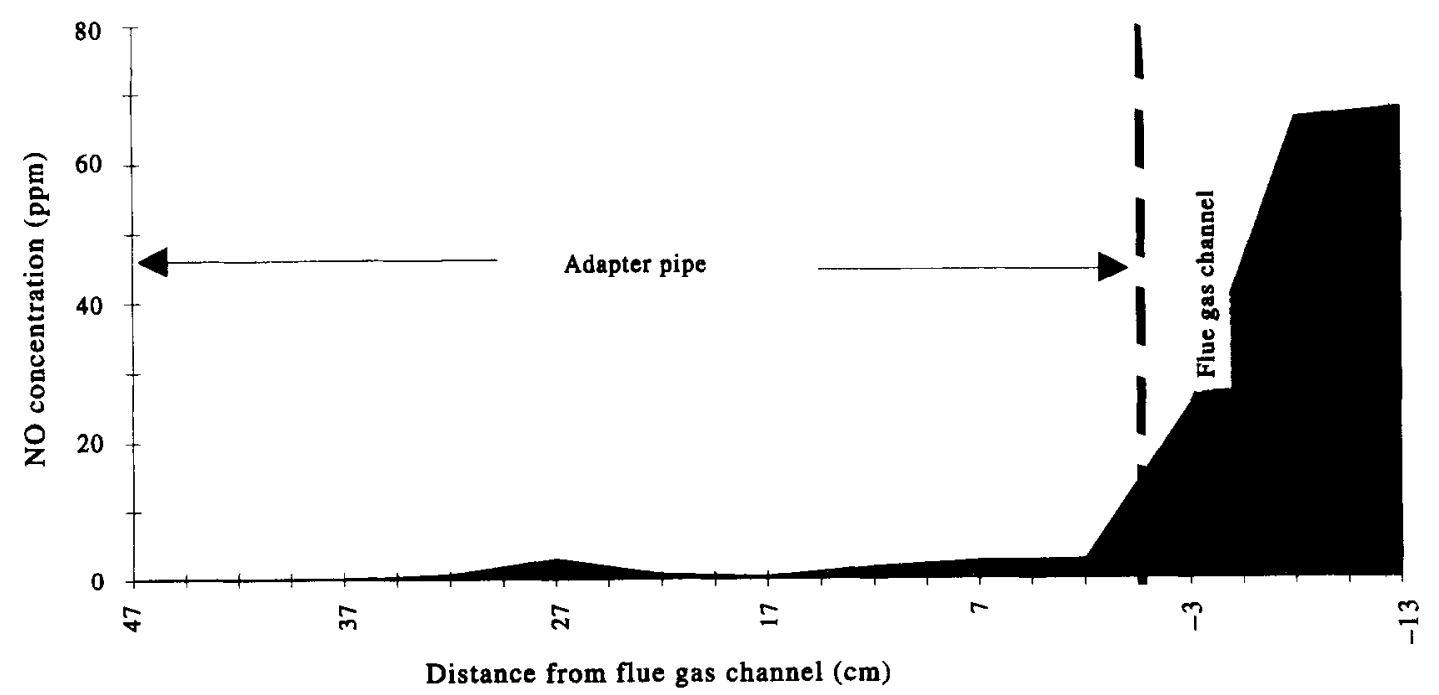

Fig. 2. The mixing ratio of NO against distance inside a pipe, which was adapted on to the wall of a flue gas channel with a diameter of $0.8 \mathrm{~m}$. 


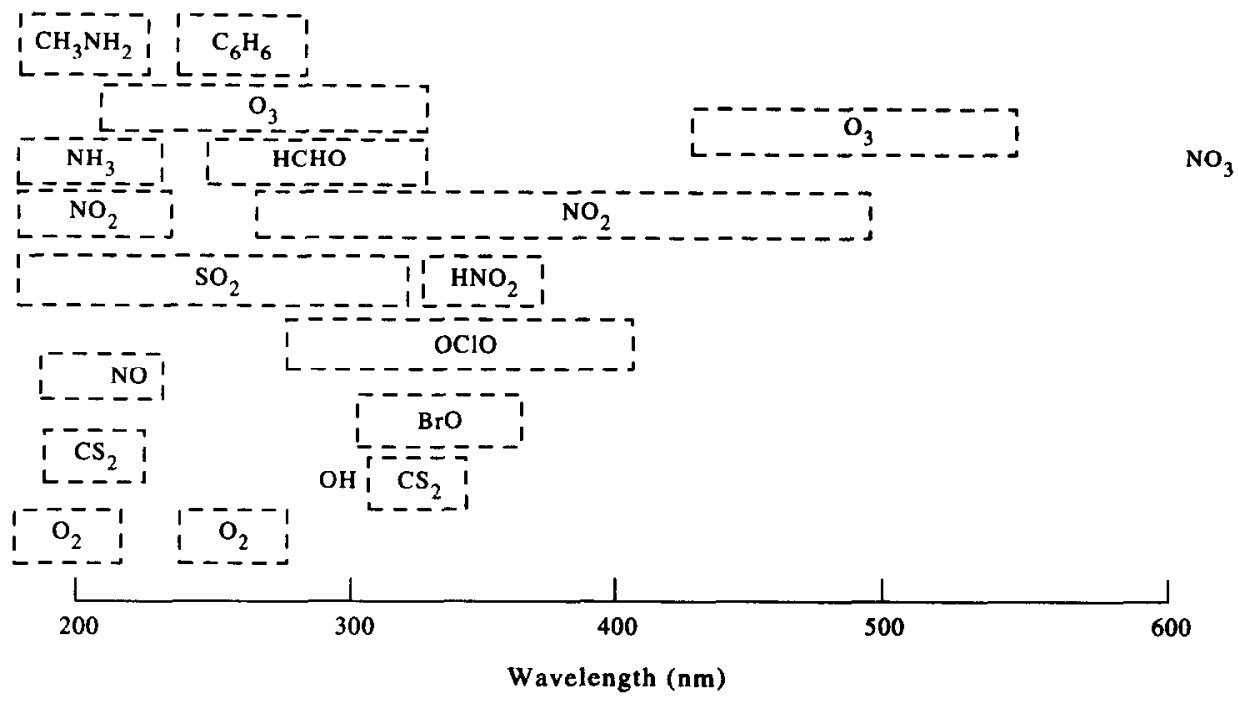

Fig. 3. Schematic spectral map in the u.v. visible region indicating absorption regions for various atmospheric species. $\mathrm{C}_{6} \mathrm{H}_{6}$ corresponds to aromatic compounds.

\subsection{General}

A schematic overview of the u.v./visible absorption bands for various gas species is shown in Fig. 3. The gas species are of interest from an atmospheric-chemical or environmental point of view, and the absorption bands can be used for DOAS measurements. The scheme is not complete, especially at the shorter wavelengths, where a large amount of additional gas species absorb as well.

The DOAS instrument used in this study could detect a minimum OD of approximately $10^{-3}$ for integration times of $6 \mathrm{~min}$, and the corresponding detection limits are shown in Table 1. These detection limits do not include spectral interferences from other species, however, which may be a serious problem in flue gas monitoring and which can degrade the detection limits considerably.

\subsection{Retrieval algorithms}

In the DOAS evaluation procedure a polynomial, $I_{\mathrm{p}}$, of low order (1st-5th) is fitted through the recorded spectrum and then the original spectrum is divided with the polynomial. The logarithm of the two divided spectra corresponds to the differential absorbance spectrum, which is proportional to the concentration of the measured molecule according to the following equation:

$$
\ln \left[\frac{I_{\mathrm{del}}(\lambda)}{I_{\mathrm{pol}}(\lambda)}\right]=\mathrm{d} \sigma(\lambda) \cdot c \cdot x=\mathrm{d} A
$$

$\mathrm{d} A=$ differential absorbance

$\mathrm{d} \sigma=$ differential absorption cross-section $\left(\mathrm{m}^{2} / \mathrm{mg}\right)$

$I_{\text {det }}=$ detected light intensity

$c=$ concentration $\left(\mathrm{mg} / \mathrm{m}^{3}\right)$

$x=$ optical pathlength $(\mathrm{m})$

$I_{\mathrm{pol}}=$ fitted polynomial

Table 1. Estimated detection limits for various flue gas species. Optical pathlength $1 \mathrm{~m}$.

\begin{tabular}{lccccc}
\hline Species & $\begin{array}{c}\text { Wavelength } \\
\text { region } \\
(\mathrm{nm})\end{array}$ & $\begin{array}{c}\text { Diff abs } \\
\text { cross sect. } \\
\left(10^{-18}\right) \\
\left(\mathrm{cm}^{2} / \mathrm{mol}\right)\end{array}$ & $\begin{array}{c}\text { Detection } \\
\text { limit } \\
(\mathbf{p p m})\end{array}$ & $\begin{array}{c}\text { Interfering } \\
\text { species }\end{array}$ & $\begin{array}{c}\text { Typical flue gas } \\
\text { mixing ratio } \\
(\mathrm{ppm})\end{array}$ \\
\hline $\mathrm{SO}_{2}$ & $290-310$ & 0.77 & 0.5 & & $1-2000$ \\
$\mathrm{NO}$ & $223-228$ & 1.9 & 0.2 & $\mathrm{SO}_{2}$ & $1-1000$ \\
$\mathrm{NH}_{2}$ & $425-435$ & 0.21 & 1.9 & & $0.05-50$ \\
$\mathrm{NH}_{3}$ & $211-218$ & 3.1 & 0.13 & $\mathrm{NO}, \mathrm{SO}_{2}, \mathrm{NO}_{2}$ & $0.1-40$ \\
\hline
\end{tabular}

+0.23-0.30 nm resolution, optical depth $=10^{-3}, 1 \mathrm{~atm}, 24^{\circ} \mathrm{C}$. 
Equation (1) is the basis for the evaluation algorithms in the DOAS technique and can be derived from the Beer-Lambert law, which was discussed in Paper I. ${ }^{9}$ From the terms in Eq. (1) the total column can be defined as $(c \cdot x)$, the optical depth (OD) as $(\sigma \cdot c \cdot x)$ and the absorbance as $(0.434 \cdot \mathrm{OD})$. The fitted polynomial, $I_{\mathrm{pol}}$, eliminates the influence of scattering from particles and molecules and other broad wavelength dependencies in the spectrum. The polynomial will also remove the broad absorption features of the molecule and will thus decrease the effective absorption cross-section yielding a pseudo-absorption cross-section which is named differential absorption cross-section. Since the polynomial is of low order it will not affect the appearance and magnitude of the narrow spectral structure which is utilized for the evaluation of the concentration.

The retrieval algorithms of the recorded DOAS spectra in this study were consistent with the procedures of Platt and Perner ${ }^{12}$ and can be summarized with the following operations which were performed on the recorded intensity spectra: (i) background subtraction, (ii) normalization with lamp- or a clean air reference, (iii) normalization with a fitted polynomial (1st-5th order) or spline, (iv) logarithmic transformation, (v) spectral fitting to calibration spectra.

The fitting procedure was performed by multiple linear regression in accordance with Bevington. ${ }^{13}$ The laboratory spectra were here fitted linearly to the experimental spectra, and a scaling factor and a baseline was thus obtained. The correlation coefficient and the standard deviation between the fitted and experimental spectra were also calculated and these were good indicators of the quality of the measurements.

The spectral regions that were being used in this study for the evaluation of NO (region II) and $\mathrm{NH}_{3}$ (regions I \& III) are shown in Fig. 4, together with absorbance features of $\mathrm{NO}, \mathrm{SO}_{2}$ and $\mathrm{NH}_{3}$. The region $295-305 \mathrm{~nm}$ was used for the evaluation of $\mathrm{SO}_{2}$.

It can be seen in Fig. 4 that the absorption of $\mathrm{SO}_{2}$ interferes in all spectral regions. It is therefore necessary to evaluate the $\mathrm{SO}_{2}$ simultaneously with the target species, by fitting a linear combination of calibration spectra to the recorded spectrum. In Fig. 5 the spectral region used for evaluation of $\mathrm{NH}_{3}$ (region III) is shown more closely together with the absorbance features of several species $\left(\mathrm{NO}, \mathrm{SO}_{2}\right.$ and $\mathrm{NH}_{3}$ ) recorded at $670 \mathrm{~K}$. This spectral region is advantageous at temperatures above $450 \mathrm{~K}$ since the spectral features of ammonia correspond to hot band transition which are fairly strong at high temperatures. In addition the absorption of $\mathrm{SO}_{2}$ is weaker in region (III) than in region (I).

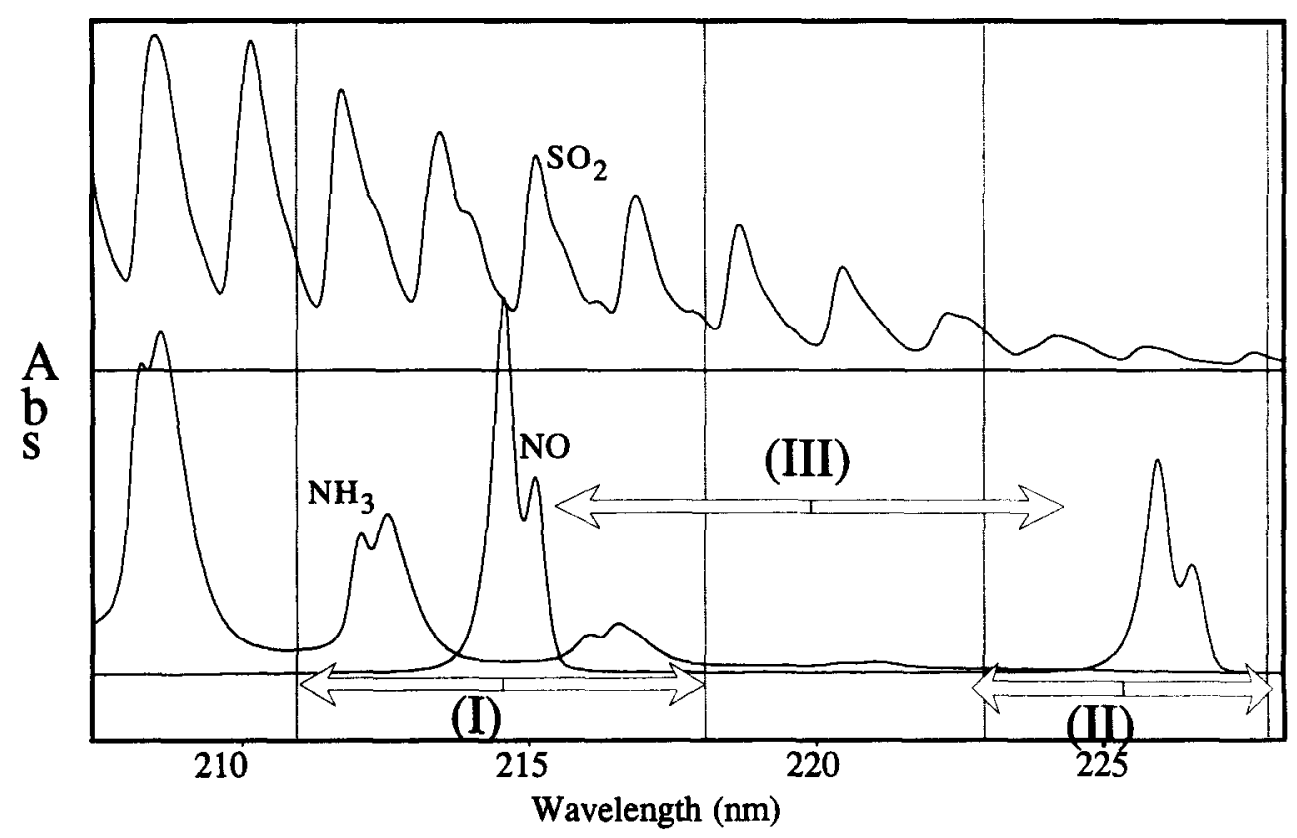

Fig. 4. Absorbance spectra of $\mathrm{SO}_{2}, \mathrm{NO}$ and $\mathrm{NH}_{3}$ (arbitrary scale) and evaluation intervals (I-III) for retrieval of these species. 


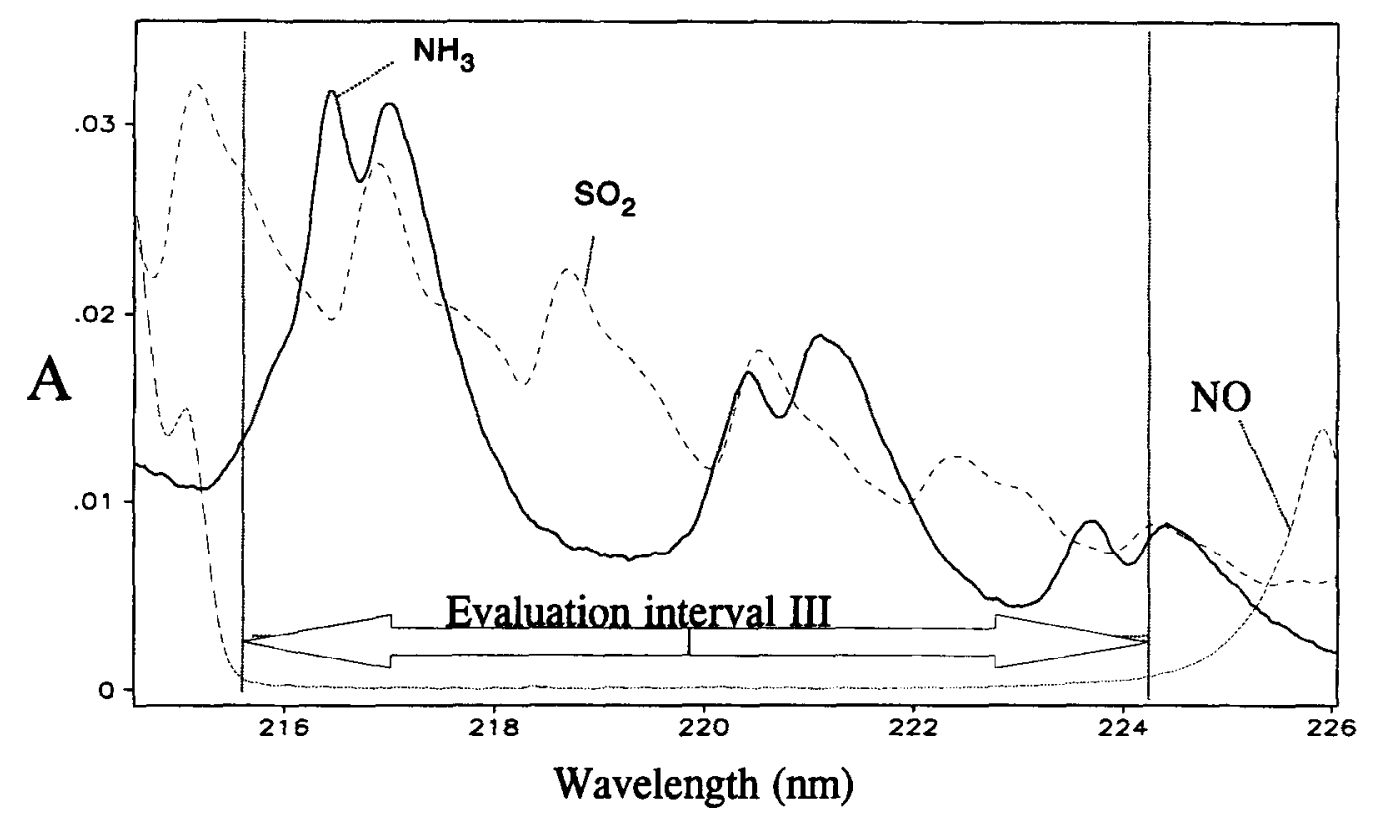

Fig. 5. An alternative evaluation region for $\mathrm{NH}_{3}$ in hot flue gases. The absorbance spectra of $\mathrm{NH}_{3}$, NO and $\mathrm{SO}_{2}$ were recorded at $670 \mathrm{~K}$ and correspond to total columns of $47 \mathrm{mg} / \mathrm{m}^{2}$ of $\mathrm{SO}_{2}, 14.3 \mathrm{mg} / \mathrm{m}^{2}$ of $\mathrm{NH}_{3}$ and $13.7 \mathrm{mg} / \mathrm{m}^{2}$ of $\mathrm{NO}$.

\subsection{Compensation for temperature effects}

In Paper $\mathrm{I}^{9}$ the effect of the temperature on the magnitude of the differential absorbance spectra was described and large relative changes were seen (up to 70\%). The differential absorbancies of $\mathrm{SO}_{2}$ for two different temperatures, 298 and $706 \mathrm{~K}$, are shown in Fig. 6, corresponding to the same total column. An increase in the magnitude of the differential structure can be seen with increasing temperature. This clearly indicates that the temperature has to be accounted for when performing DOAS measurements in a hot flue gas. The most accurate way to compensate for the temperature effect is to use calibration spectra recorded at the same temperature as that of the flue gas. This requires measuring a standard set of calibration spectra for the target species over a large temperature range. This is however time consuming and rather difficult, as was described in

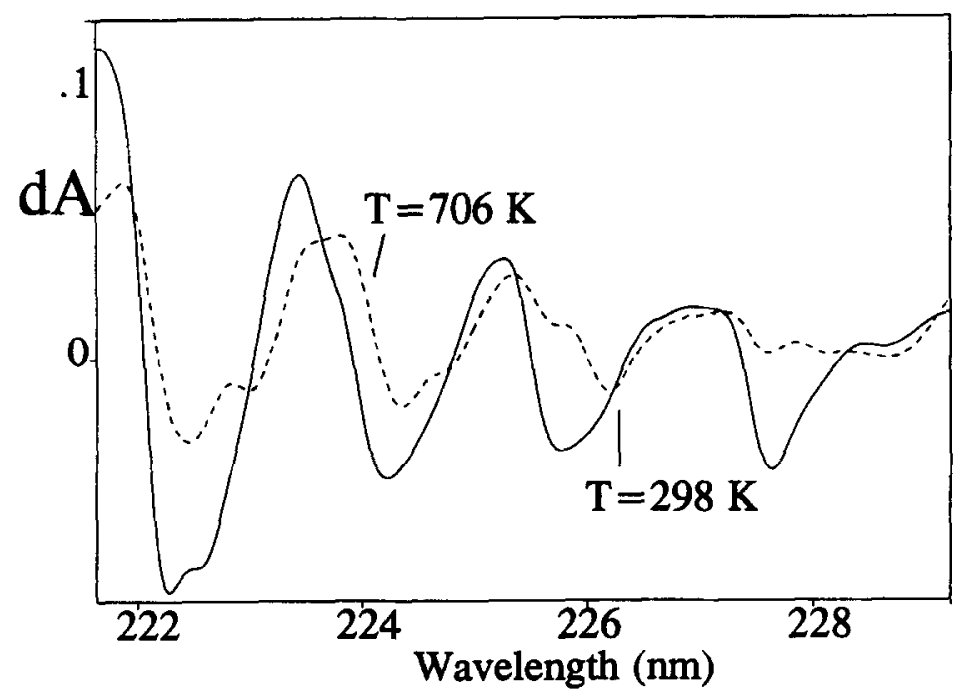

Fig. 6. Differential absorbance spectra of $\mathrm{SO}_{2}$ at $298 \mathrm{~K}$ and at $706 \mathrm{~K}$ (total column $=236 \mathrm{mg} / \mathrm{m}^{2}$ ). 
Paper I, ${ }^{9}$ and requires calibration cells that can be temperature controlled. In addition there is today an increasing tendency to use published high resolution absorption cross-sections for calibration purposes within the DOAS-community ${ }^{14}$ and these are only available in a limited range of temperatures.

An additional compensation method for the temperature effect has been evaluated in this study, which seems promising. Here one takes advantage of the fact that the temperature effect causes quantitative rather than qualitative changes in the differential absorption spectra, as was shown in Paper $I^{9}{ }^{9}$ A single room-temperature calibration spectrum can therefore be used in the spectral evaluation and the retrieved total columns can be compensated for the temperature effect afterwards.

In Paper $I^{9}$ it was shown that the relative temperature dependence of the differential absorption cross-sections, denoted by $F(T)$, could be described by the Boltzmann-like equation given in Eq. (2), with the parameters shown in Table 2.

$$
F_{\text {temp }}(T)=K_{1}-K_{2} \cdot \mathrm{e}^{-(K 3 / T)}
$$

\subsection{Compensation for nonlinearity effects}

In the DOAS technique the Beer-Lambert law is assumed to be valid, and it states that the absorbance is directly proportional to the total column. At large total columns deviations from this linear dependence may be obtained due to limited instrumental resolution (so called nonlinearity effect). This was thoroughly described in Paper II. ${ }^{10}$

In similarity to the temperature effects it was found that the nonlinearity effects mainly caused quantitative changes in the spectral features of the species studied. It is therefore possible to compensate for the nonlinearity effect after the actual spectral recording and cvaluation procedure.

From the experimental data in Paper $\mathrm{II}^{10}$ a compensation function, $F_{\text {lin }}$, was obtained by polynomial fitting [Eq. (3)].

$$
\mathrm{F}_{\text {lin }}\left((c \cdot x)_{\text {app }}\right)=1+A_{1} \cdot(c \cdot x)_{\text {app }}+A_{2} \cdot(c \cdot x)_{\text {app }}^{2}+A_{3} \cdot(c \cdot x)_{\text {app }}^{3}
$$

where $(c \cdot x)_{\text {app }}$ corresponds to the apparent total column derived from the recorded DOAS spectra and $A_{1}$ to $A_{2}$ correspond to fitting coefficients. The compensated, true, total column will then be obtained according to:

$$
(c \cdot x)_{\text {true }}=F_{\text {lin }}\left((c \cdot x)_{\mathrm{app}}\right) \cdot(c \cdot x)_{\mathrm{app}}
$$

The obtained coefficients $A_{1}$ to $A_{3}$ for the experimental data in Paper II $^{10}$ are given in Table 3 . Shown is also the linear region for each species (the linear region is here defined as where the apparent concentration deviates more than $1 \%$ from the true concentration).

In Fig. 7 a linearity plot is shown for simulated NO spectra. The simulated spectra were described in Paper II. ${ }^{10}$ The apparent optical columns as derived from recorded DOAS spectra are shown against true total column. The compensation function, $F_{\text {lin }}$, is also shown as well as the linearized data after the apparent total columns were multiplied with the linearity function according to Eq. (4).

\subsection{General evaluation procedure}

The measurement methodology for the performance of DOAS in-situ measurements in flue gases can be divided into several steps:

Table 2. Parameters for the temperature scaling factor functions. Temperature region $290 \mathrm{~K}-700 \mathrm{~K}$.

\begin{tabular}{lccccr}
\hline Species & $\begin{array}{c}\text { Wavelength } \\
\text { region }(\mathrm{nm})\end{array}$ & $\begin{array}{c}\text { Resolution } \\
(\mathrm{nm})\end{array}$ & $K 1$ & $K 2$ & \multicolumn{1}{c}{$\begin{array}{c}K 3 \\
(\mathbf{K})\end{array}$} \\
\hline $\mathrm{SO}_{2}$ & $290-310$ & 0.23 & 1.624 & 2.257 & 391.755 \\
$\mathrm{SO}_{2}$ & $223-228$ & 0.30 & 5.612 & 5.517 & 52.858 \\
$\mathrm{NO}$ & $223-228$ & 0.30 & 1.171 & 0.827 & 483.946 \\
$\mathrm{NH}_{3}$ & $216-225$ & 0.24 & & + & \\
\hline
\end{tabular}

+Equation (2) is not valid for $\mathrm{NH}_{3}, F(T)=1.166031-1.21025 \cdot 10^{3} \cdot T$ $+3.011412 \cdot 10^{-6} \cdot T^{2}-2.701077 \cdot 10^{-9} \cdot \mathrm{T}^{3}$. 
Table 3. Linear regions $\left(25^{\circ} \mathrm{C}, 1 \mathrm{bar}\right)$, and parameters for the nonlinearity compensation function.

\begin{tabular}{|c|c|c|c|c|c|c|}
\hline \multirow[b]{2}{*}{ Species } & \multirow{2}{*}{$\begin{array}{l}\text { Region } \\
\text { (nm) }\end{array}$} & \multicolumn{2}{|c|}{$\begin{array}{l}\text { Linear region } \\
\text { (upper limit) }\end{array}$} & \multirow[b]{2}{*}{$A_{1}$} & \multirow[b]{2}{*}{$A_{2}$} & \multirow[b]{2}{*}{$A_{3}$} \\
\hline & & $\left(\mathrm{mg} / \mathrm{m}^{2}\right)$ & (OD) & & & \\
\hline $\begin{array}{l}\mathrm{NO} \\
\mathrm{SO}_{2} \\
\mathrm{NH}_{3} \\
\mathrm{SO}_{2} \\
\mathrm{NO}_{2}\end{array}$ & $\begin{array}{l}223-228 \\
223-228 \\
212-217 \\
295-305 \\
425-435\end{array}$ & $\begin{array}{r}10 \\
90 \\
40 \\
700 \\
3500\end{array}$ & $\begin{array}{l}0.04 \\
0.05 \\
0.4 \\
0.6 \\
0.8\end{array}$ & $\begin{array}{r}1.583 \mathrm{e}-3 \\
1.255 \mathrm{e}-4 \\
-1.910 \mathrm{e}-3 \\
6.374 \mathrm{e}-5 \\
-2.198 \mathrm{e}-5\end{array}$ & $\begin{array}{r}4.796 \mathrm{e}-6 \\
1.788 \mathrm{e}-7 \\
6.026 \mathrm{e}-5 \\
-4.960 \mathrm{e}-9 \\
6.790 \mathrm{e}-9\end{array}$ & $\begin{array}{c}-1.463 \mathrm{e}-9 \\
9.453 \mathrm{e}-11\end{array}$ \\
\hline
\end{tabular}

(i) Recording and averaging of $10^{3}-2 \cdot 10^{4}$ spectral scans during $20-360 \mathrm{sec}$.

(ii) Retrieval of the total columns of the target species by spectral fitting of the recorded spectra to room temperature calibration spectra.

(iii) Arithmetic compensation of the temperature and nonlinearity effect according to Eq. (5).

$$
(c \cdot x)_{\text {comp }}=F_{\text {lin }}\left(\frac{(c \cdot x)_{\text {app }}}{F_{\text {temp }}(T)}\right) \cdot \frac{(c \cdot x)_{\text {app }}}{F_{\text {temp }}(T)}
$$

(iv) Conversion of the compensated total column values to mixing ratios according to Eq. (6).

$$
\operatorname{DOAS}_{\mathrm{comp}}(\mathrm{ppm})=\mathrm{const} \cdot(c \cdot x)_{\mathrm{comp}} \cdot \frac{T}{x \cdot p}
$$

where $p$ corresponds to the pressure, $T$ to the flue gas temperature and $x$ to the optical pathlength. The importance of measuring the flue gas temperature correctly should be noted, since it is included in both Eqs. (5) and (6). The final value given by Eq. (6) will correspond to the path averaged mixing ratio of the target species in the flue gas channel.

For $\mathrm{NH}_{3}$ it is usually not possible to use the methodology above for measurements in flue gases. This is due to the fact that the qualitative absorption features of $\mathrm{NH}_{3}$ change significantly with the temperature and that the absorptions of $\mathrm{SO}_{2}$ and $\mathrm{NO}$ interfere strongly, and actually dominate the features in the recorded spectrum. In order to evaluate a small total column of $\mathrm{NH}_{3}$ in this environment it is extremely important to eliminate all spectral structures of both $\mathrm{SO}_{2}$ and $\mathrm{NO}$.

The previously described procedure is therefore replaced by a more tedious procedure which is based on the recording of a large set of calibration spectra for the two interfering species $\mathrm{SO}_{2}$ and

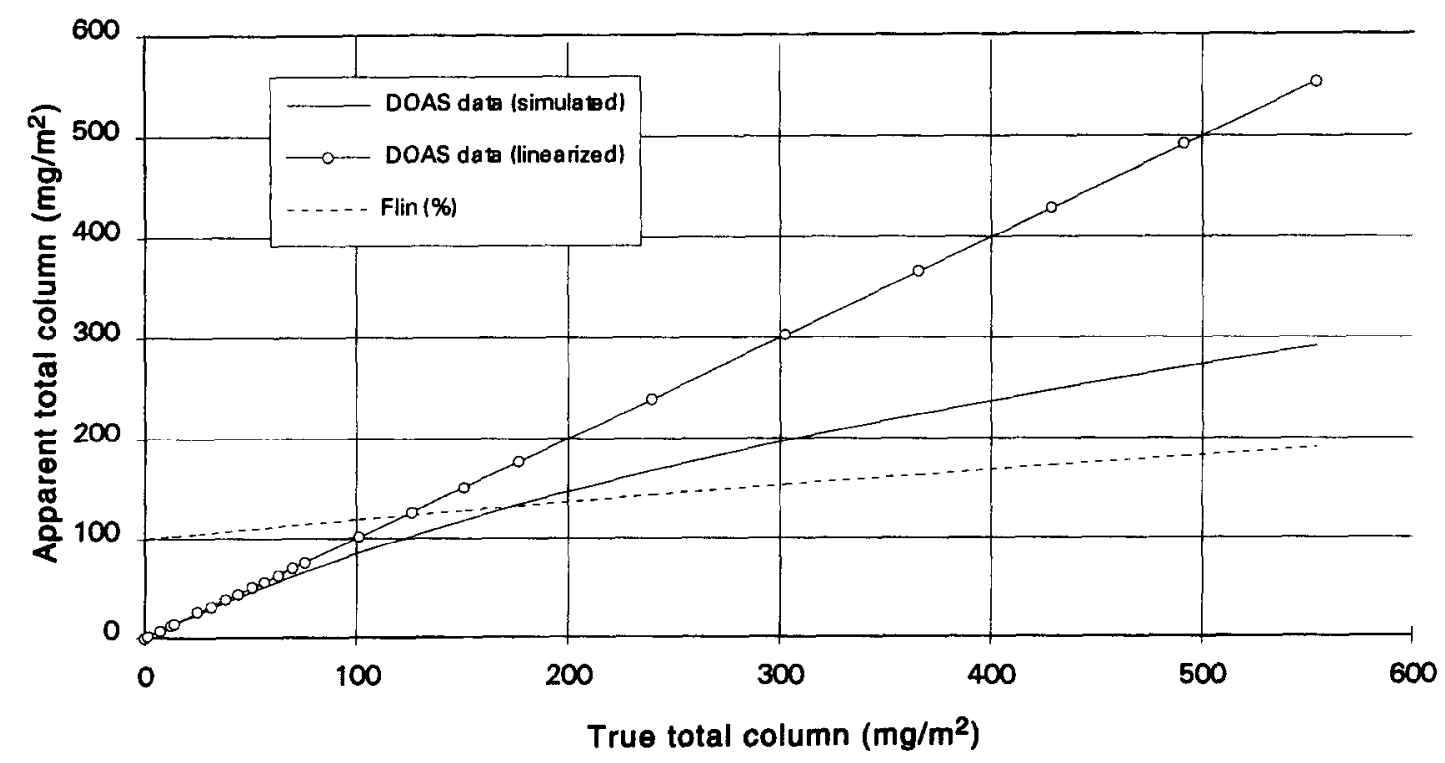

Fig. 7. Apparent total column of NO evaluated by DOAS as a function of true total column at $300 \mathrm{~K}$. 
NO, over a large temperature and total column range. The measurements are then performed in the following way: first the total columns of $\mathrm{NO}$ and $\mathrm{SO}_{2}$ in the flue gas are retrieved from the recorded spectra by evaluation in spectral region II (Fig. 4), in which the $\mathrm{SO}_{2}$ absorption is quite weak. Calibration spectra of $\mathrm{SO}_{2}$ and $\mathrm{NO}$ which have been recorded at the actual flue gas temperature and corresponding to the same total columns which are present in the flue gas, are then used together with a calibration spectrum of ammonia to evaluate the total column of ammonia. The latter evaluation is performed either in spectral region I or III, depending on the flue gas temperature as was previously discussed in Sec. 3.2. The calibration spectrum of $\mathbf{N H}_{3}$ has been recorded at the actual flue gas temperature.

\section{FIELD MEASUREMENTS BY DOAS}

In order to investigate the temperature and the nonlinearity effects, field experiments were conducted in which $\mathrm{NO}, \mathrm{SO}_{2}$ and $\mathrm{NH}_{3}$ were measured in combustion plants. The concentration of the species studied were obtained by using the evaluation procedure described in Sec. 3.

In Fig. 8 measurements of $\mathrm{SO}_{2}$ are shown which were conducted both by DOAS and by a conventional, dry extractive, reference method in which the flue gases were extracted through Teflon tubings held at the ambient temperature. Water was then removed by condensation before analyzing the concentration of the $\mathrm{SO}_{2}$ with a u.v. absorption instrument (Binos 1000). The measurements were conducted in the flue gas channel of a fluidized bed combustor (12 MW), located in Göteborg, in which high sulfur coal was burned and calcium was added in order to remove the sulfur. The DOAS instrument described in Sec. 2.1 was used. The evaluation was performed in the spectral region $295-305 \mathrm{~nm}$, using a 5th order polynomial to derive the differential absorbance.

The DOAS measurements were performed in-situ, over the cross-section of a flue gas channel after a cleaning stage in which particulate matter were removed with a filter. The flue gas channel had a diameter of $0.8 \mathrm{~m}$, the temperature was $413 \mathrm{~K}$, the pressure was $0.95 \mathrm{MPa}$ and the mixing ratio of water was $10 \%$. The optical measurement path was placed in front of a large fan and the gas flow was therefore turbulent, thus preventing temperature and concentration gradients. The reference instrument extracted flue gas in the same location as where the DOAS measurements were conducted.

The path averaged mixing ratios obtained from the DOAS and labeled by "raw" in Fig. 8, were derived by a standard spectral evaluation of the recorded spectra using room temperature

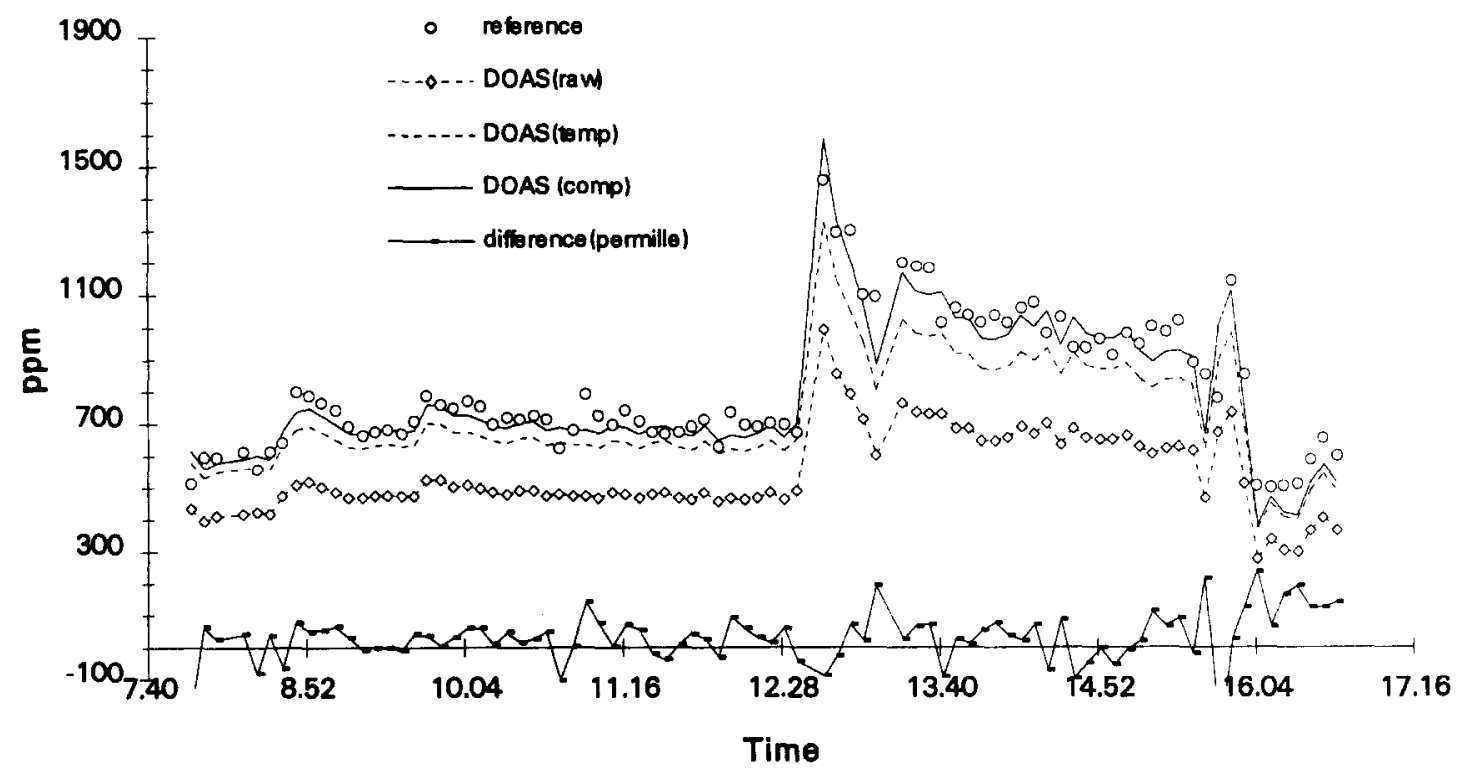

Fig. 8. Measurements of $\mathrm{SO}_{2}$ with DOAS and with an extractive reference instrument in a flue gas channel of a fluidized bed combustor $\left.(T=413 \mathrm{~K}, p=0.95 \mathrm{MPa}), \mathrm{VMR}_{\mathrm{H}_{3} \mathrm{O}}=10 \%\right)$. 
calibration spectra. The DOAS data were then compensated for temperature effects according to Eq. (2) (temp) and nonlinearities according to Eq. (5) (comp). The mixing ratios measured by the reference instrument (reference) are also shown in Fig. 8 in addition to the relative difference (in per mille) between the final compensated DOAS data and the reference instrument data.

The mixing ratios obtained from the DOAS instrument and the reference instrument in Fig. 8 have been plotted against each other in Fig. 9. The raw DOAS data and the final DOAS data which was compensated for the nonlinearity and temperature effects are shown. In addition least-square fits of all the data in Fig. 9 were performed and these are also shown for the raw, temperature compensated and temperature-nonlinearity compensated DOAS data [fit(raw), fit(temp) and fit(comp)]. If the DOAS and reference instrument would measure the same concentrations, the slope between the two would be equal to unity. It can be seen that the temperature and nonlinearity compensation data improves the slope of the fit from 0.6 to 0.99 , yielding a residual discrepancy of only $1 \%$.

The temperature compensated data shown in Figs. 8 and 9 were obtained by evaluating the recorded DOAS spectra with a calibration spectrum of $\mathrm{SO}_{2}$ which was recorded in the laboratory at $293 \mathrm{~K}$ at a total column of $236 \mathrm{mg} / \mathrm{m}^{2}$. The retrieved $\mathrm{SO}_{2}$ concentrations were then compensated for the temperature by the use of Eq. (5). A more straightforward evaluation manner would be to use a calibration spectrum of $\mathrm{SO}_{2}$ recorded at the actual flue gas temperature, which in this case was $413 \mathrm{~K}$. In Fig. 10 results are shown comparing the two above mentioned manners of compensating for the temperature effect. Calibration spectra recorded at 293 and $385 \mathrm{~K}$, respectively, were used in the spectral evaluation and then Eq. (5) was utilized to compensate for a flue gas temperature of $413 \mathrm{~K}$. It can be seen that the two procedures for temperature compensation yield very similar results. The relative difference between the two results is also plotted in Fig. 10 and it can be seen that it is more or less constant at $2 \%$. This implies that the temperature compensation can be performed in an arithmetic manner by the use of Eq. (5), instcad of the recording of calibration spectra at the flue gas temperature, which can be rather time consuming and difficult.

NO was measured at the same location as the $\mathrm{SO}_{2}$ and the physical conditions in the flue gas channel were thus the same for the measurements of the two species. The NO was evaluated in region II (Fig. 4). In order to evaluate $\mathrm{NO}$ properly, $\mathrm{SO}_{2}$ had to be evaluated simultaneously since

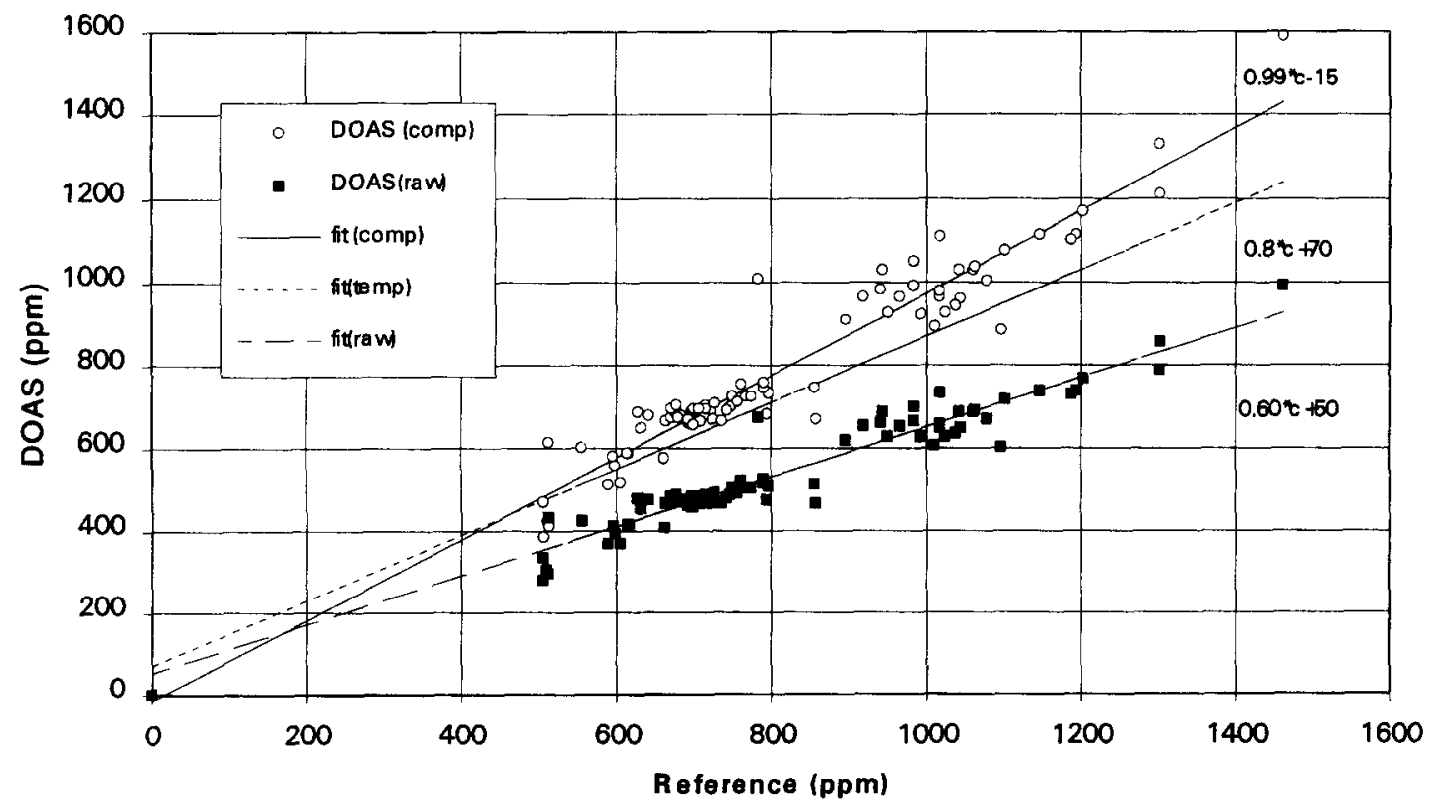

Fig. 9. Mixing ratios of $\mathrm{SO}_{2}$ from the DOAS instrument versus mixing ratios from the extractive reference instrument. 


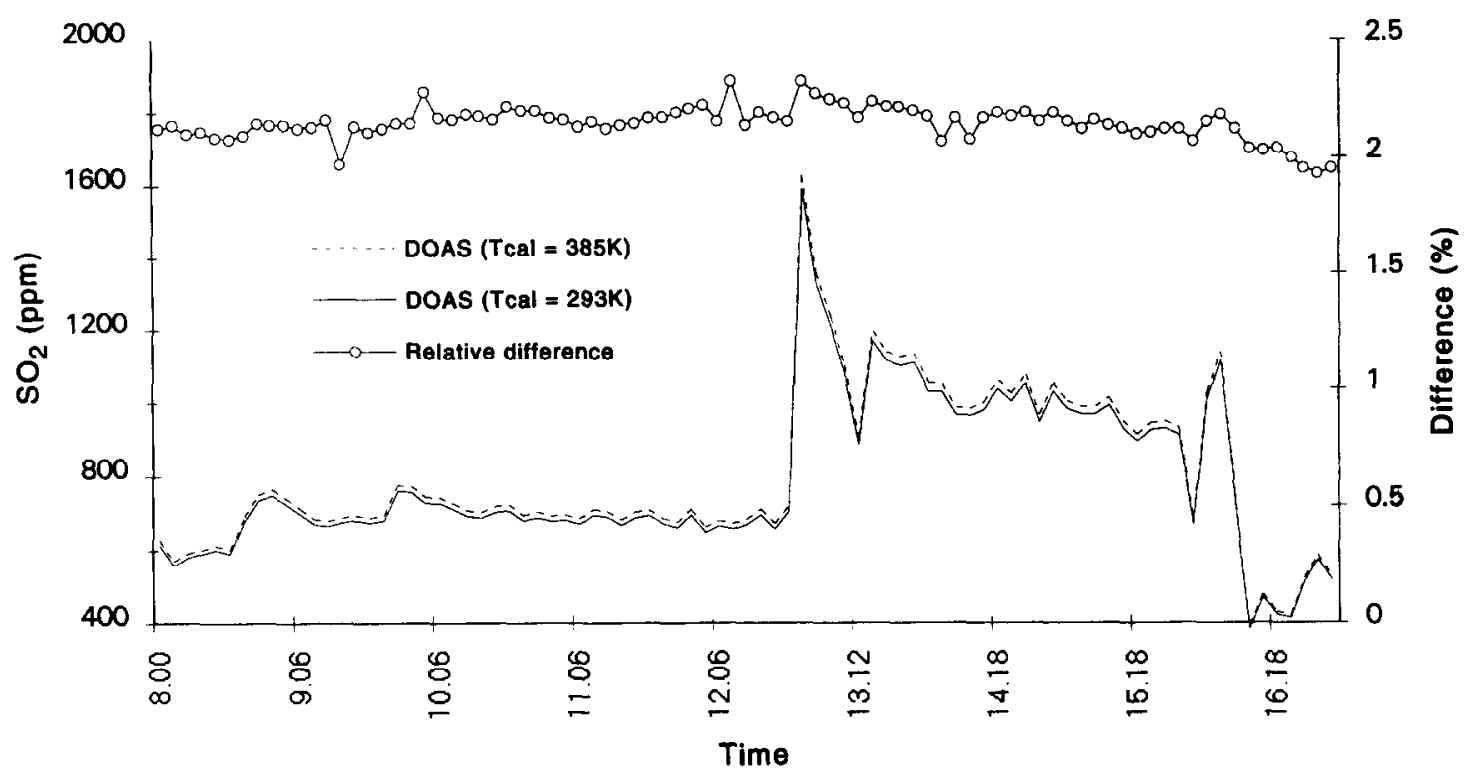

Fig. 10. Comparison of different temperature compensations of $\mathrm{DOAS} \mathrm{SO}_{2}$ data. Spectral evaluation by using calibration spectra recorded either at 293 or at $385 \mathrm{~K}$ and then applying Eq. (5) are shown.

the two species both absorb in the spectral region used. A 5th order polynomial was used to derive the differential absorbance. Conventional extractive measurements were performed by using a chemiluminescence instrument in conjunction with the extractive system previously described. Measurements of NO with DOAS and with the reference system are shown in Fig. 11. The huge increase in the NO concentrations were caused by addition of iron filings into the FBC and this has been described by Amand. ${ }^{15}$ The temperature compensated (temp) and temperature + nonlinearity compensated DOAS data (comp) are displayed in Fig. 11 together with the data from the chemiluminescence measurements (reference). The DOAS data, with temperature and

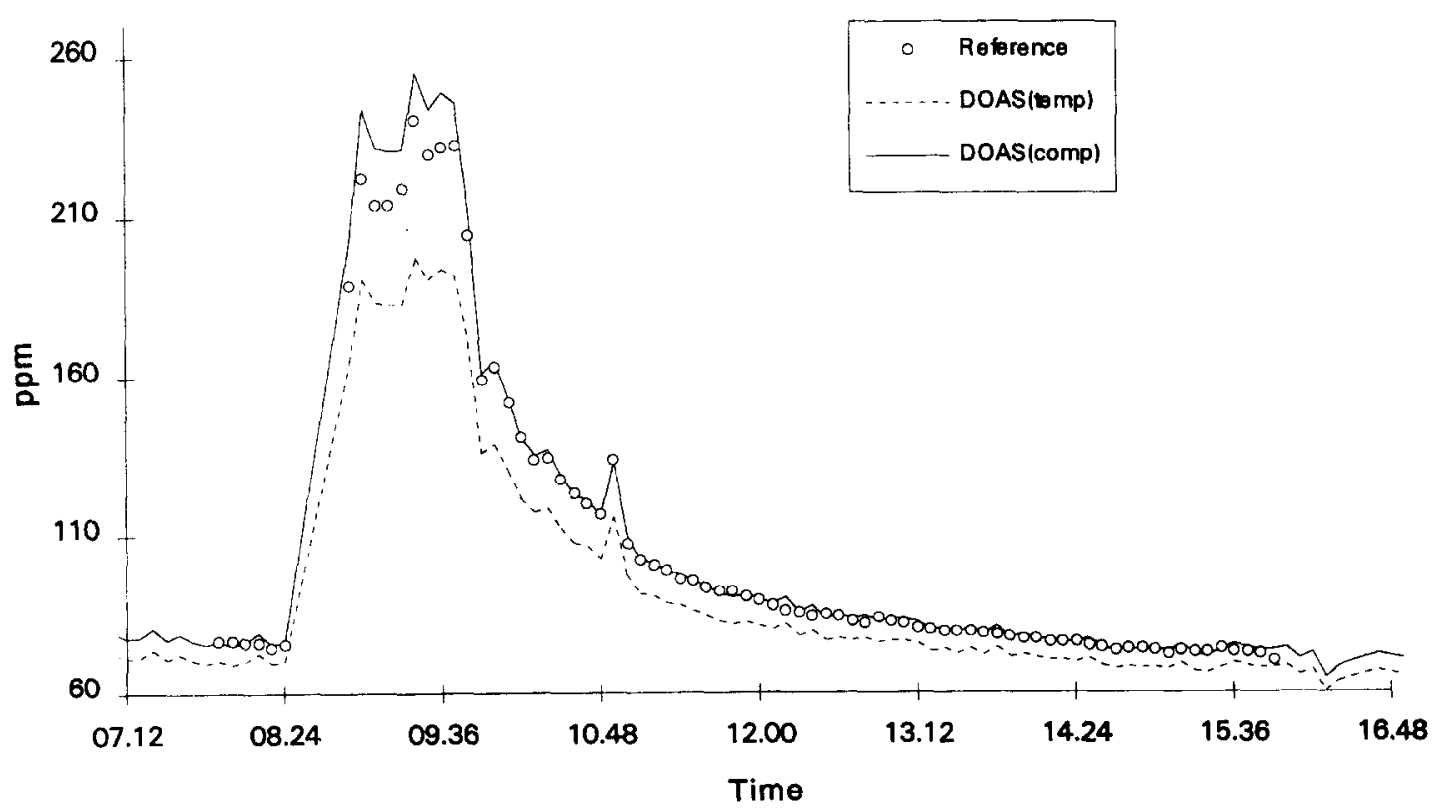

Fig. 11. Measurements of NO with DOAS and a conventional extractive reference system. 


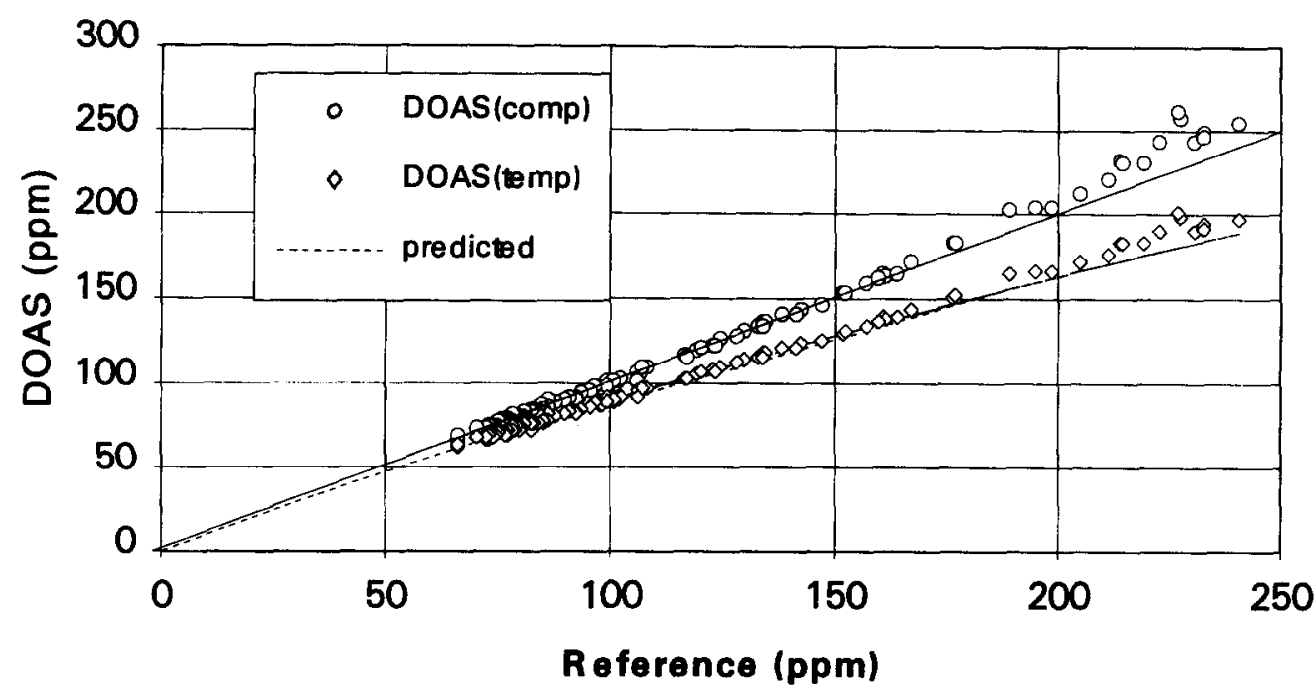

Fig. 12. Temperature and nonlinearity compensated DOAS values (comp) of NO versus the reference concentration. Shown also are the DOAS data prior to the nonlinearity compensation (temp) and their predicted behavior as obtained from the laboratory results in Paper II.

nonlinearity compensation applied, correlates well with the reference data, below mixing ratios of $160 \mathrm{ppm}$.

The mixing ratios of NO retrieved from the DOAS have been plotted against the mixing ratios from the reference instrument in Fig. 12. Both the temperature compensated data (temp) and finally compensated DOAS data (comp) are displayed. The nonlinearity compensation makes the data linear up to $160 \mathrm{ppm}$, although there is a constant discrepancy of approximately $2 \%$. Above mixing ratios of $160 \mathrm{ppm}$ the nonlinearity compensated DOAS data were considerably higher (up to $10 \%$ ) than the reference data and this will be discussed further on. The nonlinear behavior that one would predict from the results in Paper $\mathrm{II}^{10}$ is also shown in Fig. 12 as "predicted".

In Fig. 13 the temperature compensation has been compared when using calibration spectra recorded at 293 and $385 \mathrm{~K}$, respectively, in the same manner as was done for $\mathrm{SO}_{2}$ in Fig. 10. The relative difference between the two evaluation procedures varies within $\pm 2 \%$.

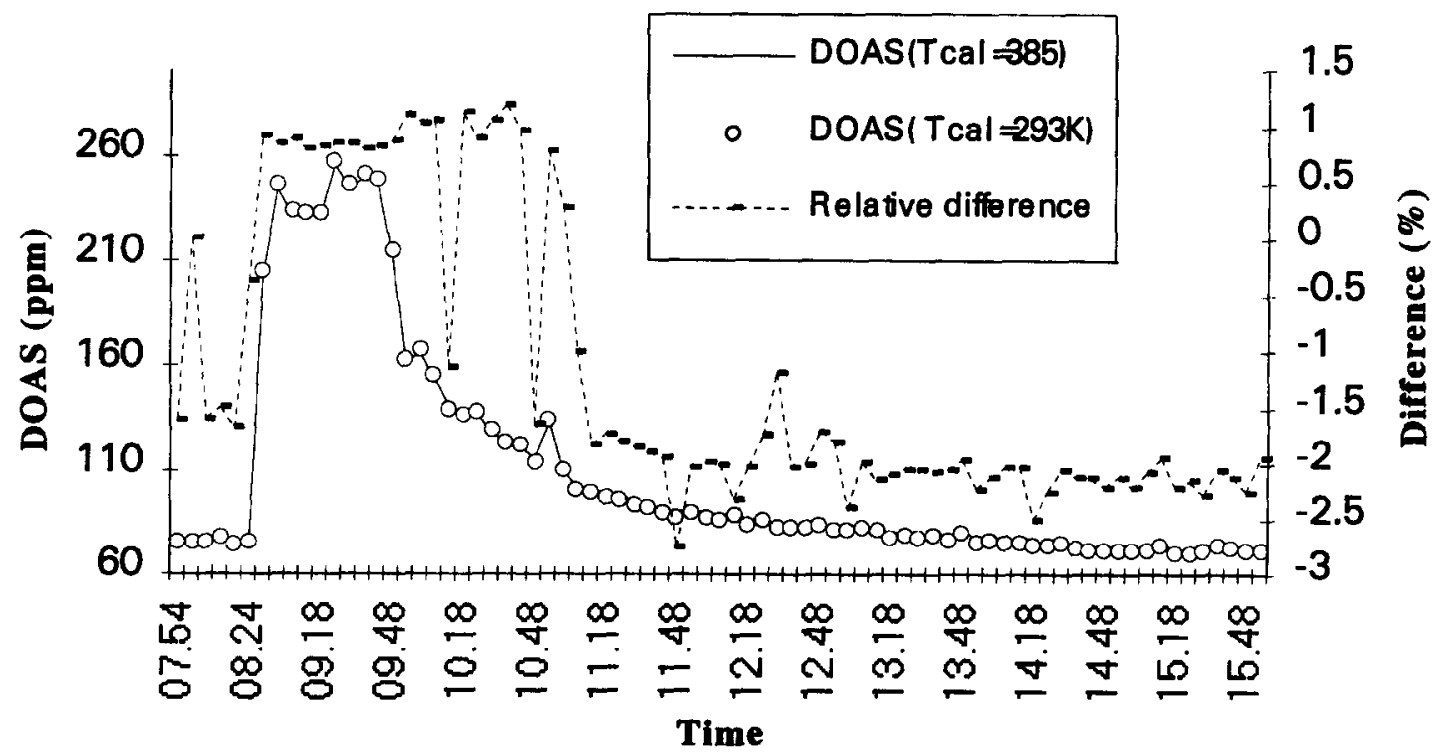

Fig. 13. Comparison of different temperature compensations of DOAS NO data. Spectral evaluation by using calibration spectra recorded either at 293 or at $385 \mathrm{~K}$ and then applying Eq. (5) are shown. 
In the results that have been shown so far, DOAS measurements of $\mathrm{SO}_{2}$ and $\mathrm{NO}$ have been compared with conventional extractive measurements. The question could be raised why a method should be developed for measuring compounds which can already be measured by conventional instruments. There are a few advantages with in-situ measurements, however, such as the elimination of the extractive system which in some cases might create measurement errors and which will give the measurements a time delay. Another advantage with DOAS is the possibility of measuring several compounds simultaneously, for instance $\mathrm{NO}$ and $\mathrm{SO}_{2}$. The elimination of the extractive system is particularly interesting when it comes to measuring polar species, which generally are extremely difficult to measure extractively.

In Fig. 14 DOAS measurements of $\mathrm{NH}_{3}$ and $\mathrm{NO}$ are displayed which were conducted in-situ, over the cross-section of a flue gas channel of a diesel fired power plant in Visby, Sweden. The measurements were performed immediately after a selective catalytic converter ${ }^{11}$ in which $\mathrm{NH}_{3}$ was injected in order to reduce the nitric oxides. The flue gas temperature was $660 \mathrm{~K}$ and the mixing ratio of $\mathrm{SO}_{2}$ was fairly low, approximately $35 \mathrm{ppm}$. The high temperature made it possible to utilize region (III) (Fig. 4) in the spectral interval. The NO together with the $\mathrm{SO}_{2}$ was evaluated in region II. A third order polynomial was used to derive the differential absorbance for $\mathrm{NH}_{3}$ while a 5 th order was used for $\mathrm{NO}$ and $\mathrm{SO}_{2}$. The optical pathlength was $2.8 \mathrm{~m}$ and 1200 spectral scans were collected before the evaluation, yielding $20 \mathrm{sec}$ mean values evaluated on-line. Some more results regarding $\mathrm{NH}_{3}$ measurements with the DOAS system shown in this study have been described by Johansson ${ }^{16}$ and Axelsson. ${ }^{17}$

\section{DISCUSSION}

It is not straightforward to perform in-situ measurements of flue gases, due to the temperature and nonlinearity effects. Other considerations to be made are that in-situ measurements require a wide knowledge of the physical and chemical environment along the probing bcam. The temperature has to be known very accurately inside the flue gas channel. If there is a temperature gradient over the measurement path this can complicate the temperature effect compensation.

Another potential problem is if there are large time variations in the flue gas concentrations (spikes), which can cause problems in the nonlinearity compensation. This is due to the fact that several thousands of spectra are co-added and averaged during a single DOAS measurement. If there are spikes in the concentration, only a fraction of the co-added spectra will be nonlinear and most of them might be in the linear absorption region. In this case the nonlinearity compensation

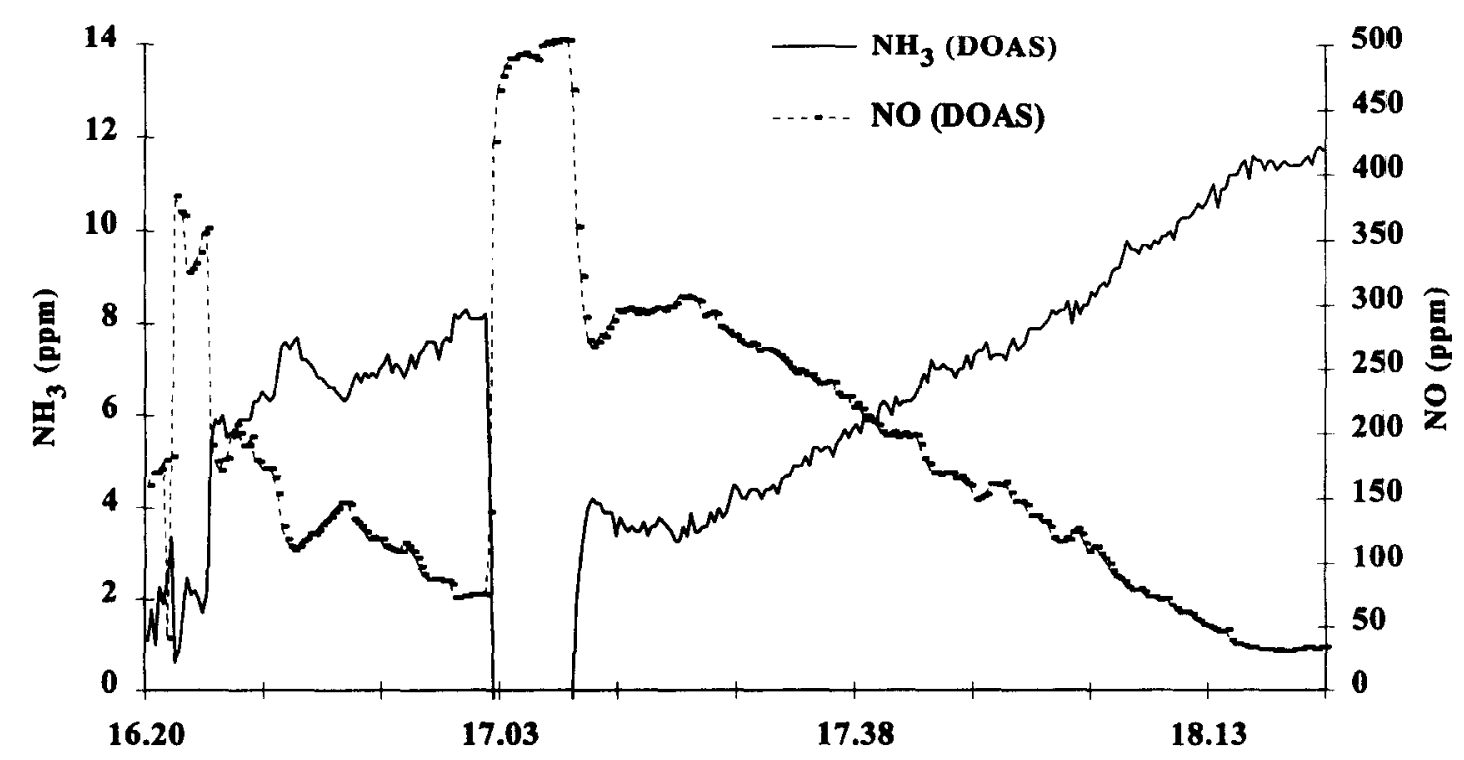

Fig. 14. DOAS in-situ measurements of $\mathrm{NH}_{3}$ and NO, performed after a SCR catalyst in a diesel fired power plant. 
will be incorrect and the only way to solve this problem is to decrease the integration time of the instrument to the time scale of the spikes.

In this study the DOAS measurements were performed at an integration time between 20 and $360 \mathrm{sec}$. With the described DOAS set-up, atmospheric measurements ${ }^{18}$ of NO have been performed with a measurement time of only $0.5 \mathrm{sec}$, however, and with a detection limit of $1-2 \mathrm{ppm}$ over $1 \mathrm{~m}$. This indicates that the measurement time could be reduced even further than $20 \mathrm{sec}$ for in-situ measurements in flue gases, with a reasonable level of performance under normal conditions.

Discrepancies were seen in Sec. 4 , between NO concentration values obtained with the DOAS technique and a conventional chemiluminescence instrument, above $160 \mathrm{ppm}$. These discrepancies are not fully understood although there are three potential explanations: (i) The conventional instrument, which was a chemiluminescence instrument, was nonlinear and did not compensate the nonlinearity well enough at large concentrations. The instrument was calibrated at $90 \mathrm{ppm}$ and was run in a measurement range between 10 and $250 \mathrm{ppm}$. The linearity was never investigated, however, above $100 \mathrm{ppm}$; (ii) the extractive measurement system was a dry extractive system. It had approximately $15 \mathrm{~m}$ long Teflon tubings held at ambient temperature and in these a fraction of the NO could oxidize ${ }^{20}$ and therefore cause reduced NO concentrations in the conventional system; (iii) the DOAS nonlinearity compensation for NO might not be entirely correct, since it may be affected by the interference from $\mathrm{SO}_{2}$. This is something we were never able to study in Paper II. ${ }^{10}$

One interesting question is whether the temperature can be quantified from recorded spectral features. This would be very useful in the compensation of the temperature effect. The temperature

(a)

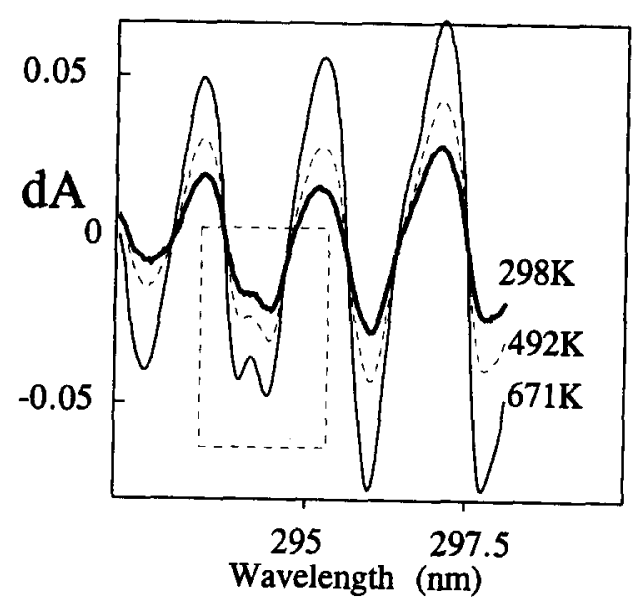

(c)

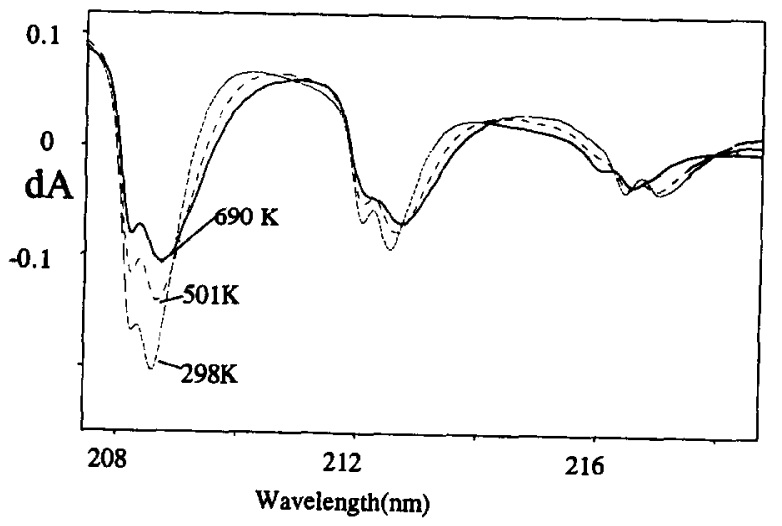

(b)

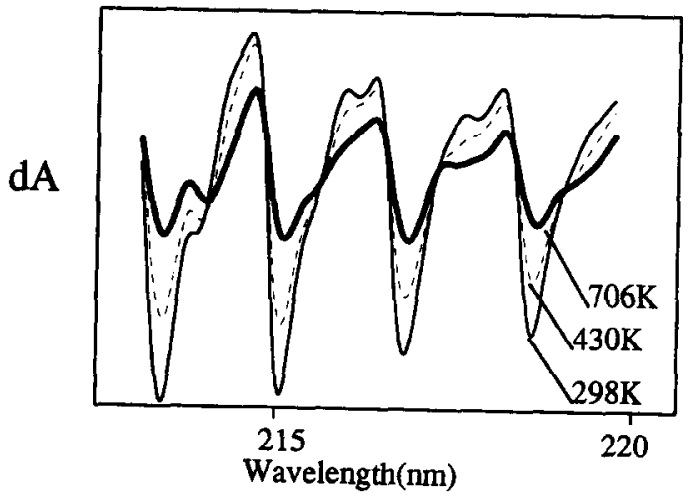

(d)

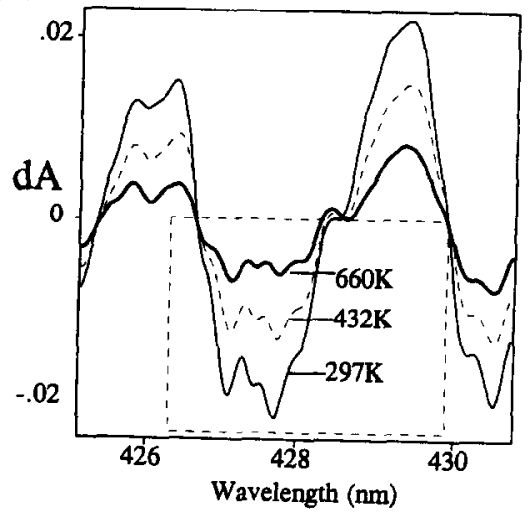

Fig. 15. Spectral differential absorbance features with a distinct qualitative change as a function of temperature for $\mathrm{SO}_{2}$ (a) and (b), $\mathrm{NH}_{3}$ (c) and $\mathrm{NO}_{2}$ (d). 
could then be evaluated, from the same spectrum from which the concentration of a certain species is retrieved. We have not put much effort into actually trying to detect the temperature, but a few suggestions of suitable spectral features which change in a distinct way with the temperature, might still be of interest and these are shown in Fig. 15. These spectra were obtained from the data that was presented in Paper I. ${ }^{9}$

\section{CONCLUSIONS}

A comparison between DOAS and conventional measurements in flue gases, indicate that the combination of temperature and nonlinearity compensation of the DOAS data decrease the difference in measured concentrations between the two measurements methods. The measurements of $\mathrm{SO}_{2}$ showed that in a concentration interval of $500-1600 \mathrm{ppm}$ at $413 \mathrm{~K}$ the resulting systematic discrepancies between the DOAS and the reference system decreased from 40 to only $1 \%$. The maximum random difference was approximately $15 \%$. For NO the systematic difference between the DOAS and the reference system decreased from 23 to $1 \%$, and with a maximum random crror of $5 \%$, for concentrations between 60 and $160 \mathrm{ppm}$. Above concentrations of $160 \mathrm{ppm}$ the concentration measured by the DOAS became $10 \%$ larger, at the maximum, than that measured by the conventional instrument. The reason for this was not understood. It was also found that the temperature effect in recorded flue gas spectra can be arithmetically compensated for by the use of Eq. (5), both for $\mathrm{SO}_{2}$ measured around $300 \mathrm{~nm}$ and for $\mathrm{NO}$ measured at $226 \mathrm{~nm}$.

The measurements of $\mathrm{NH}_{3}$ were not compared with any other instruments, but they demonstrated the versatility of the DOAS technique for time resolved in-situ measurements with an integration time of only $20 \mathrm{sec}$, and also the feasibility of measuring several species simultaneously.

In an experiment it was found that diffusion of the target gas into the adapter pipes of the instrument can cause an overestimation of the total column with approximalely $3 \%$, when using a short optical path of only $0.8 \mathrm{~m}$ and this indicates that one should be cautious when using short pathlengths.

Acknowledgments-Financial support is gratefully acknowledged by the Thermal Engineering Research Association, Sweden (Project No. B7-010/B7-020), and by the Nordic Industrial fund (Project No. 90 1669).

\section{REFERENCES}

1. IPCC, 1992: Climate Change, The IPCC Scientific Assessment, WMO/UNEP, J. P. Houghton, B. A. Callander, and S. K. Varney, eds., Cambridge Univ. Press, Cambridge (1992).

2. J. O. Reuss and D. W. Johnson, Acid Deposition and the Acidification of Soils and Waters, Ecological Studies 59, Springer, Berlin (1986).

3. P. Crutzen, Pure Appl. Geophys. 106-108, 11,385 (1973).

4. P. Crutzen, Composition, Chemistry, and Climate of the Atmosphere, H. B. Singh, ed., van Nostrand Reinhold (1993).

5. H. Edner et al, SPIE 1269, 114 (1990).

6. R. Gall, D. Perner, and A. Ladstätter-Weisenmayer, Fresenius J. Anal. Chem. 340, 646 (1991).

7. G. W. Harris et al, Workshop on Optical and Laser Remote Sensing, Monterey, CA, 8-11 Feb., p. D3-1 (1982).

8. H. Axelsson, H. Edner, B. Galle, P. Ragnarson, and M. Rudin, Appl. Spectrosc. 40, 1654 (1990).

9. J. Mellqvist and A. Rosén, JQSRT 56, 187 (1996).

10. J. Mellquist and A. Rosén, JQSRT 56, 209 (1996).

11. H. Bosch et al, Catalysis Today 2, 369 (1988).

12. U. Platt and D. Perner, Workshop on Optical and Laser Remote Sensing, Monterey, LA, 8-11 Feb., p. D2-1 (1982).

13. P. R. Bevington, Data Reduction and Error Analysis for the Physical Sciences, McGraw-Hill (1969).

14. C. Camy-Peyret et al, J. Atmos. Chem. 23, 51 (1996).

15. L. Åmand, Dissertation, ISBN 91-628-1457-5, Chalmers Univ. of Technology and Gothenburg Univ., Gothenburg (1995).

16. A. Johansson, H. Axelsson, and J. Mellqvist, Proc. of Optical Sensing for Environmental Monitoring, Atlanta (October 1993). 
17. H. Axelsson, C. Brunström, A. Johansson, J. Mellqvist, T. Jaeger, K. Karlsen, K. H. Haugholt, A. Semb, J. Lindström, S. Sommer, and H. Mikkelsen, Project No. 90 1669, Nordic Industrial Fund (1993).

18. J. Mellqvist, Å. Sjödin, H. Axelsson, S. Mclaren, and D. Stedman, IOth World Air Congress, Helsinki (1995).

19. H. Harnevie and D. Cooper, Swedish Thermal Engineering Research Association, Report 517 (1994). 